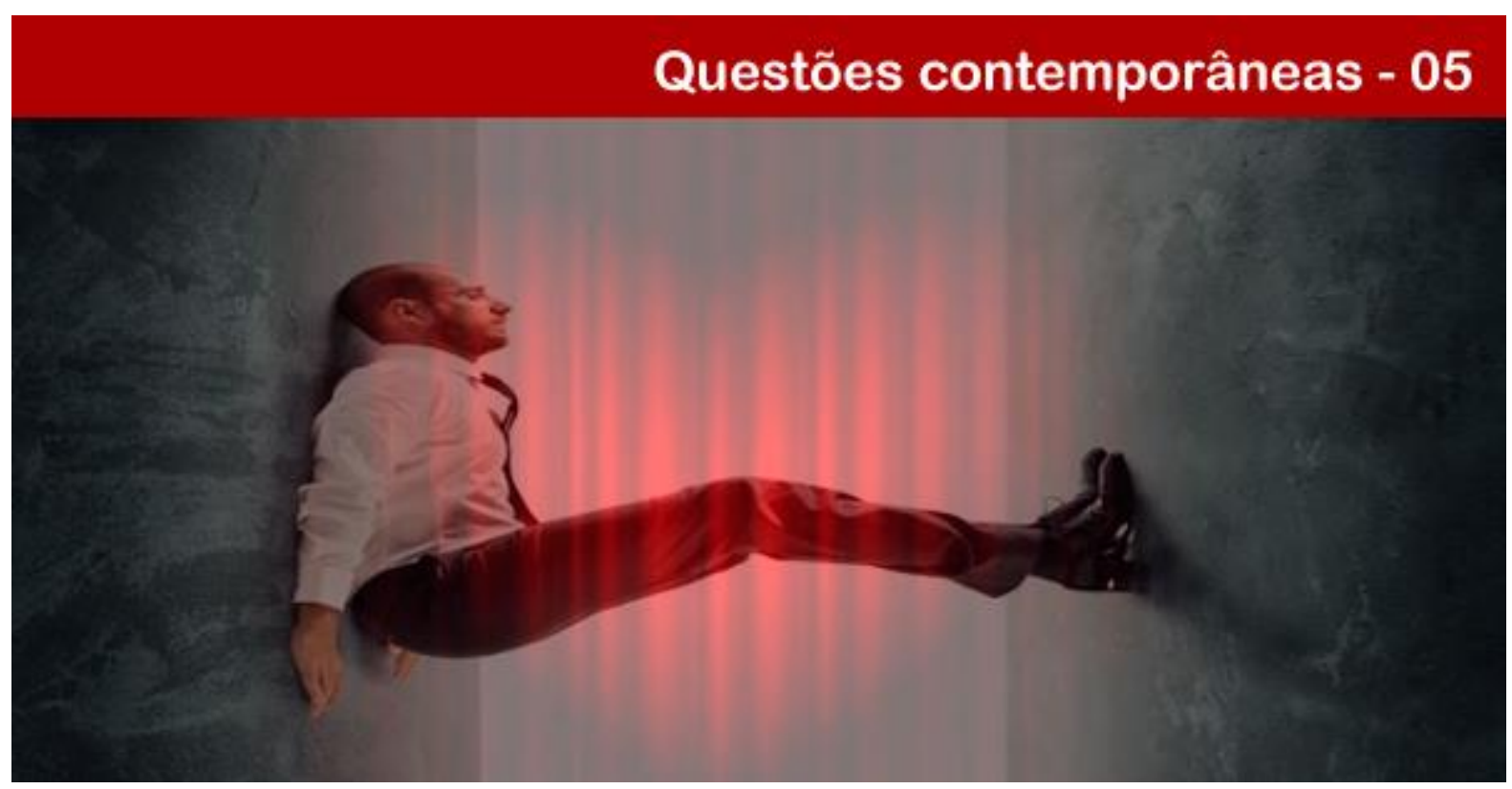

\title{
PAIXÃO OU DOENÇA? CONSIDERAÇÕES ACERCA DA PATOLOGIZAÇÃO DO MEDO E DOS PARADOXOS DA LIBERDADE
}

O medo devora a alma Herner Werner Fassbinder

We have nothing to fear but fear itself Franklin D Roosevelt

\begin{abstract}
Marcio Acselrad
Professor Titular da Universidade de Fortaleza. Professor do Centro Universitário Unichristus. Formado em Psicologia pela Universidade Federal do Rio de Janeiro. Mestre e Doutor em Comunicação pela UFRJ. Pesquisador do LABGRACA: Laboratório de Estudos do Humor e do Riso e do LAEPCUS: Laboratório de Estudos sobre Psicanálise, Cultura e Subjetividade do Programa de Pós-Graduação em Psicologia da Unifor. Coordenador e Curador do Cineclube Unifor e do Cineclube Gazeta-Unichristus. E-mail: macselrad@gmail.com.
\end{abstract}

Resumo: A proposta central deste artigo é pensar a problemática relação entre pathos e saúde. Ao utilizarmos o termo original grego, evidenciamos que pathos não se restringe à doença, patologia, distúrbio, privilegiando a abordagem segundo a qual pathos é mais bem traduzido por paixão. Do pathos, se sofre, mas não necessariamente de forma patológica. Para conduzir nossas discussões, trabalharemos sobre uma de nossas mais presentes e intensas paixões: o medo, principalmente a partir da ideia de um medo derivado, social e potencialmente paranóide. Nossa hipótese é que, com o incremento de liberdade advindo da era moderna, sofremos um consequente e paradoxal aumento de insegurança e de medo derivado dada a diminuição do aconchego que provinha do mundo comunitário. Concluímos com algumas considerações sobre o medo e a liberdade a partir do modelo social criado por Aldous Huxley em "Admirável Mundo Novo". O método utilizado para a escrita do artigo foi a revisão bibliográfica.

Palavras-chave: Medo. Pathos. Paixão. Doença. Liberdade.

\section{PASSION OR DISEASE? - CONSIDERATIONS ON THE PATHOLOGIZING OF FEAR AND THE PARADOXES OF FREEDOM}

Abstract: The central proposal of this article is to think the problematic relationship between pathos and health. By using the original Greek term, we highlight that pathos is not restricted to disease, pathology or disturbance,

\section{POLÊM!CA $\mid$ LABORE}

Polêmica - Revista Eletrônica da Uerj - Rua São Francisco Xavier, 524, $1^{\circ}$ andar

bloco D, sl.1001 • Tels.: +55 21 2334-4088 / 4087 • http://www.e-publicacoes.uerj.br/index.php/polemica/index http://www.labore.uerj.br • laboreuerj@yahoo.com.br 
favouring the approach according to which pathos is best translated by the word passion. We suffer from the pathos, but not necessarily in a pathological form. To conduct our discussions, we will work on one of our most intense passions: fear, mostly from the idea of a derivative, social and potentially paranoid fear. Our hypothesis is that, with the increase of freedom from the modern era, we suffered a consequent and paradoxical increase of insecurity and of derived fear, given the decrease in the warmth that came from the communitarian world. We conclude with some considerations on fear and freedom based on the social model created by Aldous Huxley in "Brave New World". The method used for writing the article was a literature review.

Keywords: Fear. Pathos. Passion. Disease. Freedom.

\section{Introdução}

No presente trabalho, buscaremos privilegiar a abordagem segundo a qual a noção de pathos, antes de significar doença, traz outra conotação: a de paixão. Do pathos, se sofre, mas não necessariamente de forma patológica. O pathos inclui, portanto, o amor, a raiva, o medo, a angústia e demais paixões que assolam a alma humana. Assim buscamos nos afastar da visão corrente e amplamente difundida de medicalização diagnóstica da condição humana, de que o pathos é algo do qual precisamos ser curados. Pathos, portanto, não é necessariamente doença, embora possamos com certa facilidade fazer com que se converta em uma. Para conduzir nossas discussões, privilegiaremos uma de nossas mais presentes e intensas paixões: o medo.

Toda criatura viva conhece o medo, que tem uma função importantíssima de preservação de indivíduos e espécies. O medo gera dois comportamentos fundamentais para a sobrevivência: a fuga e a agressão. Isso temos em comum com várias outras espécies animais. O que é exclusivo de nossa espécie é o que Bauman (2008) chama de medo derivado, o medo social, culturalmente reciclado, em que pessoas que interiorizaram uma visão de mundo que inclua a insegurança e a vulnerabilidade recorrem rotineiramente, mesmo na ausência de ameaça genuína, às reações adequadas a um encontro imediato com o perigo. $\mathrm{O}$ medo secundário, portanto, tem capacidade de autopropulsão, produzindo um sintoma exclusivamente humano: a paranoia, isto é, a presença do medo na ausência de uma causa real.

A falta de esperança é assustadora. Incerteza significa medo. Não admira que sonhemos com um mundo utópico, sem acidentes, regular e previsível. Um mundo que simplesmente não existe. Sonhamos com a solidez, acordamos com a incerteza. O medo é escuro. Na escuridão, tudo pode acontecer. A luz, ao contrário, tranquiliza, ilumina, esclarece. Não é a toa que, de Platão aos pensadores do século XVIII, a metáfora da luz é usada como sinônimo de conhecimento. E quando quiseram deixar evidente a visão que tinham do período

\section{POLÊM!CA $\mid$ LABORE}

Polêmica - Revista Eletrônica da Uerj - Rua São Francisco Xavier, 524, $1^{\circ}$ andar

bloco D, sl.1001 • Tels.: +55 21 2334-4088 / 4087 • http://www.e-publicacoes.uerj.br/index.php/polemica/index

http://www.labore.uerj.br • laboreuerj@yahoo.com.br 
pré-moderno, os pensadores modernos não hesitaram em denomina-lo Idade das Trevas. Também não causa surpresa que o próprio Platão, ao definir sua cidade ideal, buscou um modelo social que minimizasse as paixões, se possível fazendo com que desaparecessem de todo. No dizer de Bauman,

[...] o que mais amedronta é a ubiquidade do medo, que pode vazar de qualquer fresta de nossos lares e de nosso planeta. Das ruas escuras ou das telas luminosas dos televisores. De nossos quartos e de nossas cozinhas. De nossos locais de trabalho e do metrô que tomamos para ir e voltar. De pessoas que encontramos e de pessoas que não conseguimos perceber. De algo que ingerimos e de algo com o qual nossos corpos entraram em contato. (BAUMAN, 2008, p 26).

Mas se viver causa morte, e se disso já temos consciência, para que o medo? Se a morte é inevitável, para que tanto medo, e principalmente, para que tanto medo derivado? Se por um lado não é possível viver sem ele, por outro é impossível viver plenamente se este medo se prolifera e atinge todas as esferas da existência. A vida é uma luta impossível de vencer, busca contínua e perpétua checagem de estratagemas que nos permitam afastar, ainda que temporariamente, a iminência dos perigos, mesmo que estejamos cientes de que a banca sempre ganha no final. Para podermos viver, precisamos deslocar a preocupação e o medo, principalmente o medo da morte, para o incinerador lateral onde possam permanecer esquecidos durante nossa duração. Este é o convite que nos faz Vilém Flusser: “A comunicação humana tece o véu do mundo codificado, o véu da arte, da ciência, da filosofia e da religião, ao redor de nós, e o tece com pontos cada vez mais apertados, para que esqueçamos nossa própria solidão e nossa morte, e também a morte daqueles que amamos". (FLUSSER, 2007, p. 91).

A modernidade iluminista seria o grande salto a frente, para longe desse medo, na direção de um mundo livre do destino cego e impenetrável - a estufa dos temores. Fim das surpresas, calamidades, catástrofes, mas também das ilusões e parasitismos. Fim dos mitos e idolatrias, início da era da razão e da criticidade. Busca de mais autonomia e liberdade para o indivíduo, doravante tratado como um ser único, individualizado, capaz e responsável por suas próprias decisões.

\section{Paradoxos da liberdade}

\section{POLÊM!CA $\mid$ LABORE}


O incremento de liberdade traz consigo uma contrapartida dramática: a diminuição e eventual desaparição da segurança, do aconchego e da certeza que vem do mundo comunitário. A comunidade (ideal) promete segurança, mas o preço é pago em liberdade. A pequena comunidade é um arranjo do berço ao túmulo. Não ter comunidade significa não ter proteção, alcançar a comunidade significa não ter liberdade.

Esta tensão paradoxal entre liberdade e segurança está claramente colocada na fábula dos porcos espinhos narrada por Schoppenhauer e retomada por Freud e que conta a trajetória de um bando de porcos espinhos durante a era glacial. Numa tentativa de se proteger do frio, os indivíduos começaram a se unir, aproximando-se uns dos outros o máximo que podiam de modo que um pudesse aquecer o outro, formando, portanto, uma comunidade de ajuda mútua. O problema é que os espinhos de cada um começaram a ferir os companheiros mais próximos, justamente aqueles que lhes forneciam mais calor, produzindo um natural afastamento. Dispersaram-se por não suportar os espinhos dos seus semelhantes, mas assim voltaram a sentir frio. Tornaram a se aproximar, pouco a pouco, com jeito, com precaução, de tal forma que, unidos, cada qual conservava uma certa distância do outro, mínima, mas suficiente para conviver sem ferir, para sobreviver sem magoar, sem causar danos recíprocos.

Quanto mais nos aproximamos uns dos outros, mais seguros nos sentimos, mas os espinhos de uns não tardam a ferir os outros, de modo que algum afastamento se faz necessário. Se nos afastamos demais, ganhamos liberdade, mas o frio (a insegurança) aparece implacável e nos força a uma reaproximação, e assim sucessiva e infinitamente. Segurança sem liberdade é escravidão, um tipo muito inseguro de segurança. Liberdade sem segurança é estar só, perdido e abandonado como no mundo descrito por Hobbes em que o homem é o lobo do homem e onde a vida é intensa e curta. De que adianta a segurança se não somos livres para gozá-la? E de que adianta ser livres se não temos o mínimo de segurança para gozar desta liberdade?

Mas afinal de contas, o que estamos defendendo quando defendemos a liberdade? Do que estamos falando quando usamos "esta palavra que o sonho humano alimenta, que não há ninguém que explique e ninguém que não entenda", (MEIRELES, 1965, p. 70) É ela um valor universal ou muda de acordo com grupos e indivíduos? É ao ser humano ou foi criada no calor dos ideais que povoaram o imaginário europeu no século XVIII? É uma ideia eterna ou varia conforme o tempo e o espaço? Malgrado o alerta da poetisa, tentemos, se não uma

\section{POLÊM!CA $\mid$ LABORE}


definitiva explicação, pelo menos alguns esboços de aproximação. Nosso objetivo, longe de alcançar uma conclusão, é lançar provocações, perguntar mais que responder.

Do ponto de vista iluminista, ser livre é saber pensar por si próprio. É ter a coragem e não ter a preguiça de pensar com a própria cabeça. Sapere aude, dizia Imanuel Kant recuperando a afirmativa de Horácio. "Tenha a coragem de fazer uso de teu próprio entendimento" (KANT, 1995, p. 11). “Ousa saber". A ideia de maioridade, utilizada por Kant, representa a passagem do homem do estado de heteronomia, em que a lei está fora do sujeito e em que ele apenas crê, para o estado de autonomia, em que ele próprio é autor consciente de sua própria lei, e ele pensa.

Liberdade é não ser nem se sentir oprimido, mas é também a abertura para um campo de possibilidades de realização. É fácil perceber sua existência quando ela é de alguma forma negada, tolhida ou retirada. O cárcere é o exemplo paradigmático. Buscamos nos libertar de tudo que nos aprisiona, como as barreiras físicas das grades de uma prisão ou as barreiras psicológicas de um relacionamento. Fugimos da opressão e da injustiça, como a realizada por regimes tirânicos e truculentos. Buscamos recursos cada vez mais desenvolvidos para nos libertar das limitações do tempo e do espaço. Buscamos ajuda na tecnologia para que possamos nos sentir cada vez mais livres. Mas será que tais objetivos são alcançados?

Seria a liberdade uma especificidade humana ou podemos dizer que haja liberdade na natureza? Um pinto saindo de dentro do ovo, uma borboleta ao deixar o casulo, não anseiam, a seu modo, por liberdade? E o mesmo que vale para o indivíduo, não podemos dizer que vale também para outras espécies? Os peixes que se tornaram anfíbios, sobrevivendo às intempéries e opressões, e transmitindo assim sua herança genética não estão também, a seu modo, buscando liberdade? Certo é que apenas com o surgimento do Homo sapiens sapiens e a produção do pensamento simbólico passamos a ter consciência do tema da liberdade. Ela então passou a ser um problema. Se ao animal basta existir, sem questionar-se sobre se é livre ou não ou sobre o modo como gasta seu tempo, ao homem, ao contrário, é imperativo que reflita. Pode abdicar de fazê-lo, é certo. Pode utilizar sua própria liberdade para apenas viver sem jamais se perguntar coisa alguma, como a velha beata do conto "História de um brâmane", de Voltaire (1979, p. 241-244). Também pode escolher não mais escolher, deixar de viver, tomando a mais filosófica e existencial das decisões: o suicídio. Mas de acordo com

\section{POLÊM!CA $\mid$ LABORE}


Sócrates e seus muitos seguidores, uma vida sem questionamentos não é uma vida que valha a pena ser vivida.

Gostamos de pensar que somos livres, que decidimos soberanamente sobre nosso destino. Não gostamos de pensar que somos determinados, que forças mais poderosas do que nós dominam nossa minúscula existência. Sentimos pena do pobre Édipo, o poderoso e justo rei de Tebas que cai em desgraça por conta de uma profecia oracular da qual não consegue se livrar. No mundo grego, a Môira, o destino, era uma deusa inexorável e nem sempre justa que guiava o caminho de cada um. Édipo busca uma resposta, é um solucionador de enigmas. Mal sabe ele que o verdadeiro enigma não é aquele colocado pela Esfinge e sim aquele colocado pelo destino. Ao perguntar por sua origem, seu passado, Édipo descobre que não é quem pensava ser. $\mathrm{O}$ passado muda o presente, o presente desencadeia o futuro. O poderoso rei transforma-se em títere.

Que fazer, portanto quando, tal como Édipos pós-modernos, nos damos conta de que não somos senhores absolutos de nossos destinos e que ideologias e corporações são muitas vezes os verdadeiros mestres por trás de nossas ações? É possível ainda utilizarmos a palavra liberdade quando tomamos consciência do papel poderoso que sobre nós exercem tais forças? É possível ser livre vivendo em um tempo em que, por toda parte, impera um sistema que capitaliza todas as forças, maquínicas e humanas, transformando vida em lucro e o resto em lixo? Pode-se falar em liberdade diante do mundo que se nos apresenta, em que grande parte da população do planeta sofre de fome e guerra desnecessariamente enquanto menos de um por cento concentra riquezas incalculáveis? Jean-Paul Sartre (1987) diria que sim.

Somos livres e fim. Independente do que se diga ou faça, e já que não existe essência ou natureza humana, o que nos resta é a liberdade. E não é pouco. Esta é a afirmação concisa que nos lega o pai do existencialismo francês. Não se trata de uma benção nem tampouco de uma maldição, embora por vezes se pareça com uma ou com outra, dependendo da circunstância. Trata-se de um destino, portanto, de certo tipo de profecia. Sartre afirma que estamos irremediavelmente condenados a ser livres. Desde que nascemos, e antes até, da mesma forma que Édipo, nosso destino está traçado: somos mortais e somos livres. E a profecia se confirma e se constrói passo a passo, dia a dia. Um destino existencial que se encontra em nossas mãos a cada instante, a cada decisão que tomamos ou deixamos de tomar. Liberdade aqui é sinônimo de responsabilidade. Não implica em fazermos o que quisermos,

\section{POLÊM!CA $\mid$ LABORE}


mas em, ao fazermos o que fazemos, assumirmos as consequências de nossos atos. Somos irremediavelmente responsáveis por tudo o que fazemos e deixamos de fazer, cada frase dita ou não dita, cada mensagem enviada ou não enviada, cada gesto produzido ou evitado. Cada domingo passado em frente à televisão.

Em sua busca por liberdade, o homem já foi longe. Já aboliu a escravidão em massa e pisou na Lua. Libertou-se da ideia de que alguém possa ser dono de outra pessoa (embora ainda não se tenha livrado da ideia de que se possa comprar o tempo da outra) e libertou-se da prisão da gravidade terrestre. A tecnologia talvez seja o grande exemplo da busca humana por mais e mais liberdade. Mas aí também reside um paradoxo. Não é sem ironia que, ao percebermos criticamente os diversos avanços tecnológicos que nos cercam, notamos que toda tecnologia, na mesma medida em que liberta, produz, por sua vez, um novo tipo de aprisionamento e, na mesma medida que aproxima, afasta.

É o que acontece na narrativa budista em que um monge descia diariamente até o fundo de um poço para pegar água. Um dia lhe foi sugerido que utilizasse um sistema de cordas e roldanas que iria facilitar sua vida, permitindo que realizasse a função em menos tempo e com mais eficiência. O sábio agradeceu o conselho, mas optou por dispensá-lo. Talvez temesse que a técnica o afastasse do mundo real, criando uma intermediação da qual ele se veria, imediatamente, prisioneiro. É o paradoxo de toda técnica e de toda tecnologia. Além disso, deveria ser muito estranha ao monge a ideia de que uma tarefa deva necessariamente ser feita no menor tempo possível de modo que se possa ganhar tempo para realizar outras tarefas. Ele não sabe que tempo é dinheiro. Mas sabe sentir o tempo do mundo.

Será que as inúmeras tecnologias, especialmente aquelas que revolucionaram as comunicações, mudando nossa percepção de tempo e espaço, não criam tanta ou mais dependência do que a liberdade que oferecem? Não nos tornamos mais vulneráveis e, portanto, menos livres quando dependemos cada vez mais de dispositivos complexos, cujo funcionamento muitas vezes desconhecemos? E o suposto tempo que ganhamos ao utilizar essas tecnologias, será que refletimos sobre a forma como ele será utilizado?

Adianta mesmo "ganhar tempo" fazendo uso de um dispositivo tecnológico comunicacional se o tempo que for ganho reverter em uma ainda maior utilização desses mesmos dispositivos? Vale a pena poupar tempo se todo ele será reinvestido na produção? Estão todos obcecados em ganhar tempo, em realizar cada vez mais tarefas em cada vez

\section{POLÊM!CA $\mid$ LABORE}


menos tempo. Mas isso é sinal de liberdade ou de uma nova forma de aprisionamento? $\mathrm{O}$ tempo ganho é realmente ganho? O fato é que na maioria das vezes o tempo que ganhamos, graças à tecnologia, acaba sendo capitalizado pela própria tecnologia e raras vezes pode ser dedicado ao ócio, à criatividade, às artes ou à filosofia. Mas que se há de fazer? Afinal, somos ou não somos livres para fazer o que quisermos de nosso tempo e de nossa vida?

A modernidade também nos trouxe outra novidade: a consciência reflexiva. Com ela ganhamos a capacidade de pensar por conta própria, sem a necessidade da ajuda de outrem desde que tenhamos a coragem de fazer uso de nosso próprio entendimento e colocar todos os mitos, toda a história e todo o passado sob o jugo da razão. Assim, o futuro pode ser construído sob novas bases, menos inocentes e mais responsáveis. O problema é que ao ganharmos a consciência, perdemos, irrevogavelmente, a inocência. Só se pode ser feliz enquanto não se sabe quão feliz se é. Se você se atrever a tomar os problemas em suas próprias mãos você nunca poderá reviver a dádiva que só pôde aproveitar no estado de inocência. $\mathrm{O}$ desencantamento do mundo ganha aqui uma dupla conotação. Por um lado, o mundo se torna menos encantado, menos mágico, passível de ser escrutinado pela ciência, tal como o processo descrito por Max Weber (2004). Por outro, acabamos por nos desencantar com o mundo, que se vê reduzido a leis mecânicas de causa e efeito.

Se na comunidade (ideal) tínhamos os laços da tradição, do sangue, da família e dos afetos (o amor, mas também o ódio), na sociedade moderna tem-se a noção de contrato, necessário à sobrevivência (inclusive psíquica) num mundo que cresce descontroladamente e em que é preciso se conviver cada vez mais com pessoas estranhas. O contrato, portanto, é a ferramenta moderna para, se não vencer o medo, ao menos criarmos mecanismos legais para podermos minorá-lo. Na sociedade anônima em que se transformaram nossas cidades, o contrato é uma forma de se poder confiar desconfiando, e assim permitir as trocas entre pessoas que não se conhecem e nem desejam se conhecer.

Muitos indícios levaram ao diagnóstico de que o projeto moderno falhou. A modernidade nos deu a Lua, a razão, a penicilina e um sem número de aparelhos eletrônicos, mas não nos livrou do medo. Ao contrário, produziu grande quantidade de novos e inimagináveis medos, fobias e doenças inconcebíveis antes do século XIX como o medo do desemprego, o trauma de guerra, a histeria, o medo de multidões, o stress, a mecanização industrial do corpo e até a síndrome da solidão virtual.

\section{POLÊM!CA $\mid$ LABORE}


Deste projeto herdamos, além de grandes avanços tecnológicos, o estado moderno. O estado encontra sua razão de ser e seu direito à obediência dos cidadãos na promessa de protegê-los das ameaças à existência. Cabe ao estado, através de seu aparato jurídico, funcionar como mediador entre os indivíduos, impedindo que se autodestruam. No entanto, no estagio atual em que nos encontramos, ele não se encontra capaz de cumprir tal promessa e garantir a soberania de seus corpos ou propriedades, de seu presente e de seu futuro. Muitas vezes é esse próprio estado o responsável por injustiças, sofrimento e mais medo, como sabem aqueles que buscam se manifestar contra seu império autoritário travestido de democracia.

Mas ainda que sua proposta seja a de proteger os indivíduos, substituindo a comunidade tradicional por um conjunto de regras e leis universais, no que tange à existência, o cidadão encontra-se entregue a seu destino e na hora do imponderável, o estado pouco pode fazer. Além do que há os que afirmam que o propósito mesmo do estado não é proteger os cidadãos uns dos outros e oferecer-lhes justiça e segurança pelo uso de leis racionais e universais, mas antes proteger os ricos dos pobres e os governantes dos governados. Neste sentido não causa surpresa o fato de que a constituição do estado moderno, liberal e democrático não apenas não diminuiu o fosso entre ricos e pobres como concentrou a riqueza de forma inimaginável nas mãos de poucas pessoas e de poucos países. Contraditório para um modelo de estado que afinal se define como liberal e democrático.

\section{Considerações Finais}

Para finalizar, iremos analisar uma proposta ousada e polêmica. Ela não nos vem pela mão de sociólogos ou cientistas políticos, mas do romance de "Admirável Mundo Novo" de Aldous Huxley (2009) Estamos em Londres no ano de 753 depois de Ford, o que corresponde, no nosso calendário, ao ano de 2616, considerando-se que Henry Ford nasceu em 1863. Após uma guerra definitiva que, como as demais, causou milhares de mortes e muito, muito medo, a razão finalmente prevaleceu e a sociedade foi dividida em castas, cada qual com sua função social pré-determinada administradas por um estado todo poderoso e onipresente. Assim os alfas governam, os betas administram, cuidam e recream, os gamas encarregam-se da burocracia, os deltas mantem a cidade limpa e os ípsilons realizam o trabalho pesado em

\section{POLÊM!CA $\mid$ LABORE}


minas, fábricas e outros ambientes insalubres. Todos felizes e bem adaptados a seus papeis sociais. A comunidade humana finalmente tornada real. Afinal a cidadania universal.

Alfas e betas são mais individualizados. As restantes castas podem produzir até noventa gêmeos idênticos a partir de um único embrião, através do método Bokanovski de clonagem; ideal para o trabalho industrial. Noventa gêmeos idênticos operando noventa máquinas idênticas. Não é a toa que Henry Ford, graças a quem a produção em massa e em série foi possível, seja o deus deste mundo novo. Do momento em que são encomendados, atendendo a demandas sociais, até o momento em que são decantados do sagrado bocal, os indivíduos são meticulosamente preparados para a função que irão desempenhar. Todos são aptos fisicamente a realizar suas funções, não importa quais sejam, e são condicionados durante o sono, através do processo de hipnopedia, a gostar daquilo que fazem. Não havendo pais ou mães, todos são irmãos. Um dos princípios hipnopédicos mais importantes diz que “Todo mundo é de todo mundo e ninguém é de ninguém". Finalmente a grande fraternidade universal apregoada pelo pensamento moderno chega.

Como não há classes sociais, mas castas, não há pobreza ou miséria, não há desemprego, roubos ou crimes de qualquer natureza. Viver tornou-se uma tarefa simples que não envolve grandes riscos. A felicidade substituiu o medo como forma de regulação social, ao contrário de outra obra importante que também trata do futuro da humanidade, o "1984" de George Orwell. No que concerne a este texto, o Admirável Mundo Novo consegue, de forma radical e inexorável, extinguir o último de nossos medos: o medo da morte, dizimado através de múltiplos condicionamentos. A morte é ressignificada, passando a ser vista como bela, útil e, portanto, feliz. Ao terminar de cumprir sua função social, o corpo humano simplesmente deixa de funcionar (não há doença, não há velhice). Os mortos são reaproveitados e seus corpos são transformados em energia, de modo que possam ainda uma vez ser úteis à sociedade, enquanto crianças aprendem que morrer é algo natural e que não há nada a temer. Sem medo da morte, o medo some. Por mais estranho que tudo isso possa parecer a nossos ouvidos demasiado humanos, a proposta não deixa de ser tentadora. Há quem diga que no livro de Huxley já não há humanidade, entraríamos assim na era do pós-humano. Para perdermos o medo, faz-se necessário que também percamos a liberdade, a própria essência do que consideramos que seja o humano. Será que estamos dispostos a fazer esta troca em nome de uma admirável vida sólida?

\section{POLÊM!CA $\mid$ LABORE}




\section{Bibliografia}

BAUMAN, Zygmunt. Medo Líquido. São Paulo: Ed. Jorge Zahar, 2008.

BECKER, Gavin. Virtudes do medo. Rocco, 1999.

FLUSSER, Vilém. O mundo codificado: por uma filosofia do design e da comunicação. São Paulo: Cosac Naify, 2007.

HUXLEY, Aldous Admirável Mundo Novo. São Paulo: Ed. Globo, 2009.

KANT, Immanuel. A paz perpétua e outros opúsculos. Lisboa: Edições 70, 1995.

LORENZINI, Roberto. Quando o medo vira doença. Paulinas, 1999.

MEIRELES, Cecilia. Romanceiro da inconfidência. Rio de Janeiro: Editora Letras e Artes, 1965.

ORWELL, George. 1984. Rio de Janeiro: Companhia das letras, 2009.

SANTOS, José Vicente Tavares. Violências, medo e prevenção. Sociologias, Porto Alegre n.20

Jul/Dez 2008. Disponível em: <http://www.scielo.br/scielo.php?script=sci_arttext\&pid=S1517-

45222008000200002\&lang=pt >. Acesso em: 15 mar. 2015

SARTRE. Jean Paul. O existencialismo é um humanismo. São Paulo: Nova Cultural, 1987.

VANIER, Alain. Temos medo de quê? Ágora, Rio de Janeiro, v. 9, n. 2, Jul/Dez. 2006. Disponível em: <http://www.scielo.br/scielo.php?script=sci_arttext\&pid=S1516-14982006000200009\&lang=pt>. Acesso em: 10 abr. 2015.

VOLTAIRE, François Marie Arouet de. Contos. São Paulo: Abril Cultural, 1979.

WEBER, Max. A ética protestante e o espírito do capitalismo. São Paulo: Companhia das Letras, 2004.

Recebido em: 21/03/2016.

Aceito em: 22/06/2016.

\section{POLÊM!CA LABORE}

